\title{
RUPTURE OF CHOROID ASSOCIATED WITH CYST OF VITREOUS*
}

\author{
BY \\ Captain Emanuel Rosen, M.C. \\ NEWARK, N.J.
}

IN the December, 1943, issue of the Brit. Jl. of Ophthal., I reported two cases of " rupture of the choroid" and having at once become more interested in this phase of traumatophthalmology I have been particularly " on the alert " for other unusual cases of choroidal rupture which paradoxically are by no means rare. Because of the uniqueness of this case I am herewith submitting a brief resume of the history along with a description of the eye findings, a fundus drawing, and pictures of the anterior eye.

In the fall of 1942 while playing soft ball, the patient, a coloured male, aged 21 years, while " batting," struck himself in the right eye with a "foul tip." The batted ball landed directly upon the summit of the right cornea, for the lid closure reaction did not occur promptly. The patient was seen immediately by his physician who told him that he had an abrasion of the cornea along with a haemorrhage of the external eye and eyelids. Cold compresses were ordered placed upon the closed eye. The lids could not be opened satisfactorily for about two weeks. When finally the patient was able to open his eyes he noted that there was definite visual impairment in his right eye. About two months after this injury I made an examination with the following observations :

Vision in the right eye was 20/200 and could not be improved with refraction. Vision in the left eye was $20 / 20$. There was no involvement of lids, lacrimal apparatus or motor function although the convergence near point was somewhat remote. The pupil of the right eye was larger than that of the left. The temporal half of the right pupil responded much more promptly than the nasal half to both light and accommodation although a definite reaction was obtained from the nasal half of this pupil.

Slit-lamp examination disclosed a small superficial horizontal scar running across the pupillary area of the cornea. The iris showed a definite break in its sphincteric portion at three o'clock. This was not a " thru and thru" break in the iris but more of a triangular patch of iris atrophy with the base of the triangle directed toward the centre of the lens. The pupil at this point was irregular and the iris had a small notch at its edge. Two other iris notches could be noted above and below this prominent triangular defect. The entire nasal half of the cornea had a

- Received for publication, August, 1944. 


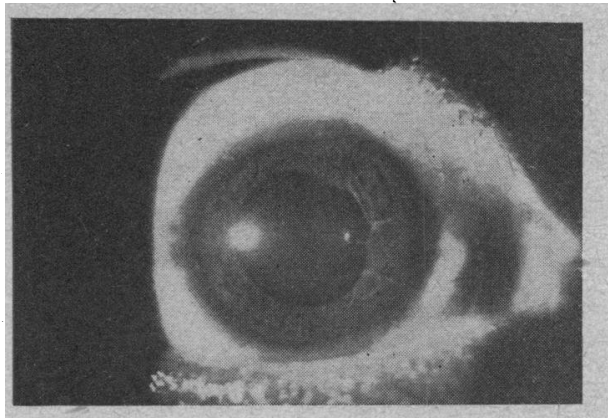

Tears in Iris, pupil dilated.

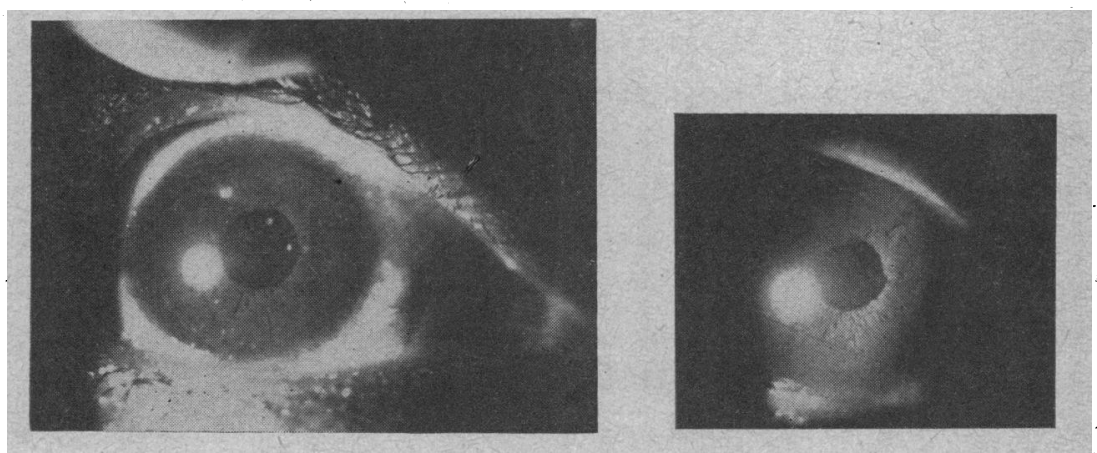

Tears in Iris, pupil undilated.

deficiency of the small "accordion" like nodules of the inner iris border.

The study of this patient's right fundus was most interesting. A very pronounced choroidal tear was present in the macular region running in a vertical.direction and being about three disc diameters in size. Over the centre of this rupture was a peculiar biconvex band whose terminals frayed out in a semi-circular astral radiation. There were no abnormalities of the blood vessels nor irregularities of pigmentation. About six disc diameters below" the disc was a very peculiar cystic structure $2 \frac{1}{2}$ times the size of the disc and shaped very much like an apple. This sphere seemed to be loosely suspended from a pedicle which would do very well for the "stem of the apple." As the patient looked upward this mass would float away and disappear, but when the patient looked down:ward the mass would gently settle back into its original position twisting slightly. upon its axis and disclosing a variation in colour phenomenon, changing from yellow to pink. Each time the cyst would settle into a pocket formed by a proliferated peripheral connective tissue mass. Its anterior inferior surface could not then be well seen since this proliferative retinal mass covered it over. 


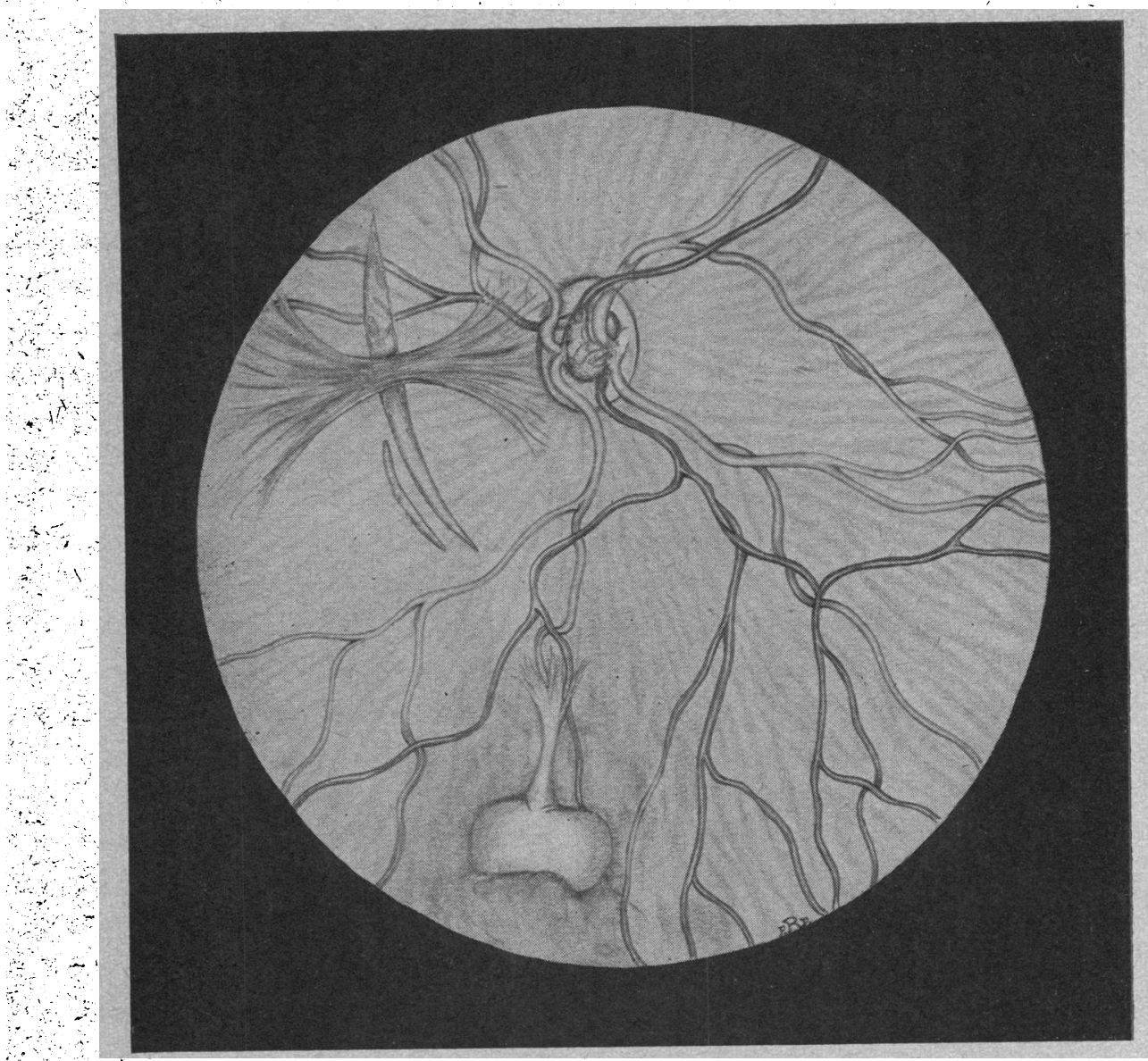

The cord-like band from which this cyst seemed to extend appeared to end mysteriously in the vitreous in a number of small digital radiations.

The systemic investigation of the patient was negative as regards any parasitic disturbance; there was no eosinophilia.

The patient was seen every few days for the next four weeks. The only observable change from day to day was an apparent variation in the colour of the cyst and a suggestion of a shrinkage process in the region where the stem joined the "apple" so that several small folds were produced in this area. About one month after the original examination, the patient's fundus was -reexamined and it was found that the cyst had ruptured. In a darkened vitreous some stem-like processes could be seen which resembled the stick to which a balloon had been tied and subsequently ruptured leaving many jagged fragments of rubber. The 
inferior portion of the vitreous was very cloudy. A poor red. reflex was secured from the inferior half of the eye. When studied under the slit-lamp the vitreous was seen to be filled with many brick red deposits unquestionably evidence of degenerated haemorrhage. When last examined the vitreous showed signs of clearing.

About ten years ago I saw a coloured female who had an exudative chorioretinitis along with some peripheral retinal " holes" and what appeared to be a cyst, shaped like a goldfish floating in the vitreous. This structure ruptured and produced a vitreous slit-lamp picture not unlike that of the case herein reported. A hole in the macula subsequently developed in this second case.

In summary I would state that this case presentation shows the relationship of direct " head on " trauma producing a tear in the sphincter of the iris along with a rupture of the choroid. The unusual occurrence of a cyst in the vitreous of traumatic aetiology indicates the tendency toward excessive proliferation and encapsulation of tissue seen in this particular race. In most cases where there is a tear in the sphincteric portion of the iris due to " head on " injuty there is more likely to occur a choroidal tear, than in cases where an iridodialysis takes place. Of course, the trauma producing the iridodialysis is not " head on " but usually lateral for the "give" occurs at the root of the iris and the zonular fibres rather than at the inner iris circle and the choroid. Wolff, who reported traumatic cysts of the vitreous in the Transactions of the Ophthalmological Society of the United(Kingdom in 1942, believes that retinal cysts frequently develop following trauma and preceding formation of retinitis proliferans.

\section{ANNOTATION}

\section{Testimonials}

Testimonials may be of many kinds including a gift presented to some one by a body of persons as an expression of appreciation; an affidavit, an official warrant, even a passport as given to vagrants, labourers, discharged soldiers and sailors; and a letter of recommendation of a person or thing. This last item as a definition dates from I571 according to the Shorter Oxford Dictionary. It is the last instance that specially concerns us, for those applying for posts on the staff of a hospital have to furnish testimonials as to their capabilities for the situation.

Looking over testimonials in after life is not unlike looking through a bundle of old school reports. Some are diffuse, some 